\title{
OFF-SEASON PERFORMANCE OF TOMATO HYBRIDS CULTIVATION UNDER NATURAL VENTILATED POLYHOUSE CONDITIONS IN NORTHERN PLAINS OF INDIA
}

\section{RAMENDRA SINGH \& JEEWESH KUMAR}

Agri Centre of Excellence, Field Fresh Foods Pvt. Ltd., Ludhiana, Punjab, India

Poly house cultivation of tomato increases in Northern plains due to high prices of raw tomato in winters in North India. It encourages tomato growers to maximize the production with suitable cultivars. Keeping in view the experiments was planned to study the off-season performance of tomato hybrids cultivation under natural ventilated polyhouse conditions in northern plains of India at experimental field of Agri. Centre of Excellence, Field fresh Foods Pvt. Ltd, Ludhiana Punjab during the winters of 2016 (30 97' latitude and 75 79' longitudes). In present investigation, the two hybrid cultivars of tomato were taken (KPS-1154 and San Marzano cv. UG-8122) to analyze their performance in off-season under covered structure. It was observed during analysis that San Marzano (cv. UG-8122) was the earliest to flower (35 days) in comparison to the KPS-1154 hybrids who take 41 day to flowering. San Marzano (cv. UG-8122) had the potential of setting maximum fruits per plant (41.3) followed by Tomato KPS-1154 (36.7). San Marzano (cv. UG8122 ) recorded the maximum yield of $4557 \mathrm{~g} / \mathrm{plant}$ and was much more variation with other tomato hybrids KPS-1154 (3215g/plant) and have the potential to be cultivated under protected conditions of Punjab. The cultivars UG-8122 (San Marzano) performed very well in winter seasons as well as in much warm temperature about $50-55{ }^{\circ} \mathrm{C}$ in poly house condition. Polyhouse tomatoes had better colour and appearance and have potential for better performance and higher fruit yield with better return.
\end{abstract}

KEYWORDS: Tomato, Offseason, Hybrid, Polyhouse, Yield \& Profit

Received: Jul 12, 2017; Accepted: Jul 29, 2017; Published: Aug 04, 2017; Paper Id.: IJASRAUG201782

\section{INTRODUCTION}

Polyhouse cultivation of vegetables offers distinct advantages of quality, productivity and favourable market prices to the growers. Vegetable growers can substantially increase their income by greenhouse cultivation of vegetables in off season as the vegetables produced in the normal season generally do not fetch good returns due to large availability of these vegetables in the market. Polyhouse vegetable production technology is very popular and adopted by Europian and Amincan countries. It allows precision farming and overcomes limitations of space and disadvantages of climate change. Production of vegetables under protected conditions is increasing worldwide. In these systems various factors of the environment such as air, temperature, humidity, atmospheric gas composition etc., are controlled. Protected cultivation in the form of Polyhouse, net houses, low tunnels, mulches etc., offers several advantages to grow crops of high quality and yields, thus using the land and other resources more efficiently. Temperature and light intensity affects fruit set, pigmentation and nutritive value of the fruits. The optimum range for fruit seeting in tomato is being $16^{\circ} \mathrm{C}$ to $22^{\circ} \mathrm{C}$ in night hours. Fruits fail to set at $12^{\circ} \mathrm{C}$ or below. Fruit set is also reduced markedly when average maximum day temperature goes above $32^{\circ} \mathrm{C}$ and average minimum 
night temperature goes above $22^{\circ} \mathrm{C}$. At temperatures below $10^{\circ} \mathrm{C}$, red and yellow colours do not develop. The ideal range for development of both red and yellow colours is $18-25^{\circ} \mathrm{C}$. Mostly greenhouses are designed to minimize or eliminate insects and diseases problems so that plants can be grown pesticide free under covered conditions. Generally all four sides of greenhouses are covered with insect proof nylon net of 40 to 50 mesh size to prevent insects, including white flies, thrips, aphids etc. Preventing insects from entering the protected structures is the best way of controlling virus and insect problems. Indeterminate tomatoes are traditionally grown in polyhouse, greenhouses, glasshouse and nethouse. However, since polyhouse tomatoes are considered to have the best quality, the indeterminate tomato is often cultivated in net houses and open fields. Worldwide, tomato extensively cultivate under protected structure for better yield and higher return. Under covered condition farmer will maintain fruit quality and harvest early for higher market returns. As tomato is an important crop under solanecious family needs much attention to increase productivity and profitability. Indeterminate varieties of tomatoes, having the character of creeping nature has great demand under covered condition. Observance of these points, present investigation on off-season performance of tomato hybrids cultivation under natural ventilated polyhouse conditions was undertaken in Punjab to select superior cultivar having the character of higher yield, good quality and earliness for more return.

\section{MATERIALS AND METHODS}

The present investigation was conducted at the Agri Centre of Excellent Farm, Field Fresh Foods Pvt. Ltd. Ladhowal, Ludhiana, and Punjab during October 2016 to March 2017 to identify superior tomato hybrids for polyhouse condition conditions. Two tomato hybrids were obtained from private sectors for this study. Seedlings were raised in portrays filled with potting mixture (Cocopeat: Perlitte and Vermiculite) with a ratio of 2:1:1. The experiment was conducted in saw tooth type naturally ventilated polyhouse located in ACE farm Ladhowal, Ludhiana. The soil of the experimental field was sandy loam in texture. Chemical analysis of the soil (top $15 \mathrm{~cm}$ ) showed a pH of 8.2, $0.48 \%$ organic carbon, $182.4 \mathrm{~kg} / \mathrm{ha}$ permanganate extractable nitrogen, $24 \mathrm{~kg} / \mathrm{ha}$ Olsen's ( $0.5 \mathrm{M} \mathrm{NaHCO3extractable} \mathrm{phosphorus} \mathrm{and} 192$ $\mathrm{kg} / \mathrm{ha}$ exchangeable potassium with a EC of $0.15 \mathrm{mmho} / \mathrm{cm}$. Transplanting was done on Oct 2016 at a spacing of $125 \times 70$ $\mathrm{cm}$ in raised beds. Standard pruning and training practices implemented for proper structure of plant for flowering and fruiting. Timely irrigation and fertilizer was applied through drip irrigation.

\section{RESULTS AND DISCUSSIONS}

The observations on both hybrid cultivar was taken on followings characters viz, Plant height $(\mathrm{cm})$, Height at flowering $(\mathrm{cm})$, Node to $\mathrm{I}^{\mathrm{st}}$ Inflorescence $(\mathrm{cm})$, Internode length $(\mathrm{cm})$, Leaf length $(\mathrm{cm})$, Leaf width $(\mathrm{cm})$, Days to flowering, Days to fruit set, Flower per cluster, Inflorescences per plant, Fruit set (\%), Pollen viability (\%), Fruit per plant, Truss per plant, Fruit per truss, Fruit length $(\mathrm{cm})$, Fruit girth $(\mathrm{cm})$, Fruit weight $(\mathrm{g})$, Fruit per plant $(\mathrm{g})$, Pericarp thickness (mm), No. of locule/fruit, No of seed /locule, TSS, Yield (t/ha), Total return (Rs./ha), Cost of cultivation (Rs./ha) and Benefit over CoC Rs/ha. The observations recorded on plant height in different tomato hybrids grown under polyhouse and ranged from 186-212 cm. The results indicated that under the polyhouse conditions tomato hybrid San Marzano (cv. UG8122 ) was the tallest with a height of $211.7 \mathrm{~cm}$. While, KPS-1154, showed plant height $186.5 \mathrm{~cm}$. Ganesan (2001) revealed that, Pusa Ruby attained maximum plant height $(2.11 \mathrm{~m})$ under greenhouse conditions. However, as per the studies of Cheema et al. (2013), tomato hybrids grown in open field conditions show ranges in between the 81 to $181 \mathrm{~cm}$. These agree with the results of Kumar and Arumugam (2010) and Reddy et al. (2013). The plants received comparatively lower light intensity than the open condition there by facilitating cell elongation and increased intermodal length leading to an increase 
in plant height. Suseela (2013) also similarly reported that the long leaf and supplementary crop canopy.

San Marzano (cv. UG-8122) was the earliest to flower (35 days) and KPS-1154 taken days to flowering 41 days. This is in agreement with the investigation in tomato by Kumar and Arumugam (2010). Commencement of flowering with minimum number of days is a desirable character since it denotes earliness. The inflorescence per plant is an important character which influences the total yield of the plant. Maximum number of inflorescence per plant was recorded in Tomato. Though the plants may produce a lot of inflorescence all of them may not bear fruits in the same way also Cheema et al., (2013) noticed the 5-10 flowers per cluster in the net house condition. Truss per plant ranged from 4.3 to 6.3 on both cultivars in natural ventilated poly house conditions. The number of fruits per truss is a genetic character and is also governed by the micro climatic condition surrounding the tomato plant under the polyhouse conditions. Tomato recorded maximum number of fruits per truss (6.3) in San Marzano (cv. UG-8122), while only 4.3 truss per plant was recorded in KPS-1154. Cheema et al., (2013) reported that tomato produced more number of fruit per cluster in the polyhouse condition due to better environment under polyhouse condtion in off season (winter season), which leads to more fruit setting. KPS-1154 registered minimum number of fruits per truss (4.3).

Table 1: Performance of Tomato Hybrids under Natural Ventilated Polyhouse Conditions

\begin{tabular}{|l|l|c|c|}
\hline \multirow{2}{*}{ S. No } & \multicolumn{1}{|c|}{ Characters } & \multicolumn{2}{|c|}{ Cultivars } \\
\cline { 3 - 4 } & & San Marzano (UG-8122) & KPS-1154 \\
\hline & Plant height (cm) & 211.7 & 186.5 \\
\hline & Height at flowering (cm) & 70.6 & 77.1 \\
\hline & Node to It Inflorescence (cm) & 12.1 & 11.2 \\
\hline & Internode length (cm) & 9.3 & 8.9 \\
\hline & Leaf length (cm) & 6.7 & 6.2 \\
\hline & Leaf width (cm) & 3.3 & 3.2 \\
\hline & Days to flowering & 35 & 41 \\
\hline & Days to fruit set & 7 & 8 \\
\hline & Flower per cluster & 7.3 & 6.7 \\
\hline & Inflorescences per plant & 25.6 & 22.1 \\
\hline & Fruit set (\%) & 61.5 & 55.3 \\
\hline & Pollen viability (\%) & 43.8 & 41.3 \\
\hline & Fruit per plant & 41.3 & 36.7 \\
\hline & Truss per plant & 6.3 & 4.3 \\
\hline & Fruit per truss & 3.7 & 3.0 \\
\hline & Fruit length (cm) & 7.4 & 5.0 \\
\hline & Fruit girth (cm) & 4.8 & 4.6 \\
\hline & Fruit weight (g) & 109.7 & 78.2 \\
\hline & Fruit per plant (g) & 4557 & 3215 \\
\hline & Pericarp thickness (mm) & 8.1 & 6.2 \\
\hline & No. of locule/fruit & 2 & 2 \\
\hline & No of seed /locule & 16 & 24 \\
\hline & TSS & 4.0 & 3.0 \\
\hline & Yield (t/ha) & 52.64 & 34.25 \\
\hline & Total return (Rs./ha) & 789,600 & 513,750 \\
\hline & Cost of cultivation (Rs./ha) & 273,975 & 246,875 \\
\hline & Benefit over CoC Rs/ha & 515,625 & 266,875 \\
\hline & & & \\
\hline
\end{tabular}

Pollen viability is one of the essential requirements for good fruit setting. Pollen viability was maximum in San Marzano (cv. UG-8122) $43.8 \%$ and in KPS-1154 (41.3). Maximum fruit set percentage was recorded in San Marzano segment cv. UG-8122) (61.5 in poly house condition; whereas KPS-1154 recorded the fruit set 55.3 per cent. Similarly, Cheema et al. (2002), and Arora et al. (2006) recorded the deviation in fruit setting entitlement. Variations in fruits setting 
percentage due to variation in pollen release under fluctuating heat stress environment. Similar results were reported by the Munshi and Kumar (2000) under greenhouse conditions. Chandra et al. (2000) found that tomato hybrid Naveen performed better under green house. Hazarika and Phookan (2005), Singh et al (2005) and Cheema et al. (2013) reported similar results under polyhouse conditions. For better utilization of light and temperature, the compensation point between photosynthesis and respiration in relation to light intensity and temperature is important. The light intensity and temperature at which photosynthesis and respiration are exactly balanced are important to make a better use of both these climatic parameters under protected conditions. A genotype exhibiting a compensation point at low light intensity and temperature may have a high photosynthetic efficiency and such genotypes perform better under shade.

Fruit length was recorded maximum, in San Marzano segment cv. UG-8122 (7.4 cm) and minimum in KPS-1154 recorded minimum girth of $5.0 \mathrm{~cm}$. The observations recorded on average fruit weight in different tomato hybrids grown under polyhouse conditions indicated that tomato hybrid, San Marzano had maximum average fruit weight (109.7 g) whereas, KPS-1154 had the minimum average fruit weight (78.2g) in poly house condition. Arora et al. (2006) and Cheema et al. (2013) reported similar variations for fruit characters under protected cultivation. As far as numbers of fruits per plant are concerned, the result indicated that under polyhouse had the potential of setting maximum fruits per plant (41.3) and KPS-1154 showed 36.7 fruit per plant. Tomato varieties varied in their reaction under polyhouse conditions than in open field conditions, as supported by the experiment conducted by Singh et al (2005) and Cheema et al., (2013). The genetic makeup of the plant decides its yield potential. But the expression of the yield is influenced by the environmental factors in which plant grows.

Economics of cultivar UG-8122 segment San Marzano under field condition was found much better in comparison of KPS-1154. The total net returned Rs. 515,525/ha was recorded by San Marzano followed by KPS-1154 in poly house condition that provided Rs. 266,875/ha. Also san Marzano condition provided maximum yield 52.64 t/ha followed by KPS-1154 with fruit yield of 34.25 tons/ha. The cultivars UG-8122 (san Marzano) performed very well in winter seasons as well as in much warm temperature about $50-55{ }^{\circ} \mathrm{C}$ in poly house condition.

Quality characters are very important in any crop especially in vegetables like tomato because they impart nutritional quality of the produce as well as processing quality. In the present study, different hybrids showed variation in quality characters like TSS, no of locule, no. of seed and Pericarp thickness. In the present study yield per plant (g) showed a wide variation from 4557g in San Marzano (cv. UG-8122). In both cultivars two locules were recorded in each locule 16 and 24 numbers of seeds were noticed in San Marzano and KPS-1154 cultivars respectively. Thickness of Pericarp 8.1 mm was found in UG-8122 cultivars and $6.2 \mathrm{~mm}$ was recorded in KPS-1154 in poly house. TSS of tomato fruit 4.0 was noticed in UG-8122 cultivars and 3.0 was found in KPS-1154. This is in consonance with the experiments conducted by Singh $e t$ al., (2005) and Suchindra et al. (2012), Cheema et al., (2013). An additional advantage of improved fruit appearance was noticed under the polyhouse tomato fruits. Fruits under shade were uniformly red colored with very good appearance.

Maximum fruit yield per plant of tomato hybrids was due to higher fruit set and higher retention of matured fruits/plant. High yield recorded by San Marzano (cv. UG-8122) might be due to the genetic potential of plant to produce fruits in less number but larger in size. Genotypic combination plays an important role in the development of fruit size and weight. For better utilization of light and temperature, the compensation point between photosynthesis and respiration in relation to light intensity and temperature is important. The light intensity and temperature at which photosynthesis and respiration are exactly balanced are important to make a better use of both these climatic parameters under protected 
conditions. A genotype exhibiting a compensation point at low light intensity and temperature may have a high photosynthetic efficiency and such genotypes perform better under shade. Quality characters are very important in any crop especially in vegetables like tomato because they impart nutritional quality of the produce as well as processing quality. An additional advantage of improved fruit appearance was noticed under the polyhouse tomato fruits. Fruits under shade were uniformly red colored with very good appearance. In this study, crop inside poly house was comparatively free from pest and disease incidence. Increased fruit yield per plant under polyhouse condition compared to open field condition due to minimum incidence of pest and insects under polyhouse was reported by Singh et al. (2012) in tomato. Influence of shade on disease incidence on tomato was reported by Kittas et al. (2009). Similar results was reported by Monica et al. (2014) and Shah and Shukla (2014).

\section{CONCLUSIONS}

Under polyhouse conditions, tomato hybrids performed well for yield and quality characters because of favorable conditions which positively influenced the morpho-phenological and physiological events of tomato plants. The differential shade responses of different hybrids are due to the inherent variability that exists among them. It is concluded that San Marzano (cv. UG-8122) were found to be the high yielding hybrids under polyhouse conditions for the area under consideration. The higher yields in these hybrids might be due to cumulative effects of early flowering, higher fruit set and higher retention of matured fruits per plant. The optimum temperature accompanied by low relative humidity inside polyhouse hasten crop development and early maturity, so growers are benefited by being able to produce higher and offseason tomato which fetched premium prices in the market.

\section{REFERENCES}

1. Arora, S. K.; Bhatia, A. K.; Singh, V. P. and Yadav, S. P. S. 2006. Performance of indeterminate tomato hybrids under greenhouse conditions of north Indian plains. Haryana J. Hort. Sci., 35(4): 292-294.

2. Chandra, P.; Arun, K.; Awani, K.; Singh, R.; Srivastava. and Mathala, J. G. 2000. Studies on vegetable cultivation in greenhouse. National Seminar on High-Tech Horticulture. Indian Institute of Horticulture Research, Bangalore. pp. 26-28.

3. Cheema, D. S., Kaur, P. and Kaur, S. 2002. Off-season cultivation of tomato under net house conditions. Acta Hort., 659: 177181.

4. Cheema, D. S., Singh, N. and Jindal, S. K. 2013. Evaluation of indeterminate tomato hybrids for fruit, yield and quality traits under net house and open field conditions Veg. Sci., 40(1): 45-49.

5. Hazarika, T. K. and Phookan, D. B. 2005. Performance of tomato cultivars for polyhouse cultivation during spring summer in Assam. Indian J. Hort., 62(3): 268-271.

6. Kittas, C.; Rigakis, N.; Katsoulas, N. and Bartzanas, T. 2009. Influence of shading screens on microclimate, growth and productivity of tomato. Acta Hortic., 807: 97-102.

7. Kumar, S. R. and Arumugam, T. 2010. Performance of vegetable under naturally ventilated polyhouse condition. Mysore J. Agric. Sci., 44(4): 770-776.

8. Monica,V. L.; Kumar, A.; Chand, H.; Paswan, S. and Sanjeev, K. 2014. Population dynamics of Tetranychus urticae Koch on brinjal crop undernorth Bihar conditions. Pest Management in Horticultural Ecosystems. 20 (1): 47- 49.

9. Munshi, A. D. and Kumar, R. 2000. Evaluation of tomato varieties under plastic green house during off-season. National seminar on Hi-tech Horticulture, Indian Institute of Horticulture research, Bangalore, pp. 45-49. 
10. Reddy, B. R.; Reddy, D. S.; Reddaiah, K. and Sunil, N. 2013. Studies on genetic variability, heritability and genetic advance for yield and quality traits in Tomato (Solanum lycopersicum L.) Int.J.Curr.Microbiol.App.Sci., 2(9): 238-244

11. Singh, A. K.; Shrivastava, R.; Gupta, M. J. and Chandra, P. 2005. Effect of protected and unprotected condition on biotic stress, yield and economics of spring summer vegetables. Indian J. Agric. Sci., 75: pp.485-487.

12. Singh, A. K., Singh, B., Sindhu, S. S., Singh, J. P. and Savir, N. 2012. Study on protected open field conditions on insect pest incidence to minimize insecticide application for quality production of high value horticultural crops. Int. J.Plant Protection, 5(1): 75-50.

13. Suchindra, R.; Sankaranarayanan, R. and Nainar, P. 2012. Studies on evaluation of tomato (Solanum lycopersicum L.) hybrids under four different growing environments for quality characters. Plant Archives 12(1): 257-258.

14. Suseela, P. (ed.). 2013. Design and management of protected cultivation in Kerala-A practical Guide-Communication centre, $K A U .366 p$. 